\title{
Anterior versus Posterior Approach in Traumatic Thoracolumbar Fractures Deemed for Surgical Management: Systematic Review and Meta-analysis
}

Terence Tan, MBBS, Joost Rutges, MD, Travis Marion, MD, Augusto Gonzalvo, MD, Sue Liew, MBBS, Joseph Mathew, MBBS, Mark Fitzgerald, MD, Marcel Dvorak, MD, Jin Tee, MD

Department of Neurosurgery, The Alfred Hospital, Melbourne, Victoria, Australia (T.T., J.T.)

National Trauma Research Institute, Melbourne, Victoria, Australia (T.T., J.M., M.F., J.T.)

Department of Orthopaedics, Erasmus MC, Rotterdam, Netherlands (J.R.)

Division of Orthopaedic Surgery, Northern Ontario School of Medicine, Ontario, Canada (T.M.)

Department of Neurosurgery, Austin Health, Melbourne, Victoria, Australia (A.G.)

Department of Orthopaedics, The Alfred Hospital, Melbourne, Victoria, Australia (S.L.)

Department of Orthopaedics, Division of Spine, University of British Columbia and Vancouver General Hospital, Vancouver, British Columbia, Canada (M.D.)

Short Title: Anterior vs posterior surgery in burst fractures

\section{Corresponding author:}

Dr. Jin Tee

Email: jtee.neurosurgery@gmail.com

Phone: +61 390765704

Fax: +61 390763740

Address: Department of Neurosurgery, Level 1, Old Baker Building, The Alfred Hospital, 55 Commercial Road, Melbourne, Victoria 3004, Australia

\section{Conflicts of Interest and Source of Funding: None declared}




\section{$\underline{\text { Abstract }}$}

Background. Uncertainties remain regarding the optimal surgical approach (anterior or posterior) in the treatment of traumatic thoracolumbar burst fractures. We aim to compare the surgical, radiological and functional outcomes in anterior versus posterior approaches in adult patients with traumatic thoracolumbar burst fractures deemed appropriate for surgical management.

Methods. A systematic review using five electronic databases (PubMed, Web of Science, EMBASE, Google scholar, Cochrane Database) and adhering to the Preferred Reporting Items for Systematic Reviews and Meta-Analyses (PRISMA) guidelines was performed. The authors reviewed comparative studies evaluating anterior versus posterior approaches in terms of clinical, surgical, radiographic and functional patient outcomes. Qualitative analysis was performed. Where suitable, meta-analysis was performed to compute pooled estimates of the differences between anterior and posterior approaches.

Results. A total of six studies (three observational, one prospective non-randomized trial, two randomized controlled trials) were included. There were no cases of neurological decline postoperatively regardless of approach. Meta-analysis demonstrates a longer duration (Mean Difference (MD) +81.68, 95\% CI 39.20 to 123.16, p <0.001) and increased estimated blood loss (MD+426.27, 95\% CI 119.84 to $732.70, \mathrm{p}=0.006$ ) for the anterior as compared to the posterior approach. No difference between approaches was found with regards to length of hospital stay, late postoperative kyphotic angle, construct failure rate, instrumentation revision rate, rate of return to work, and total hospital charges. Limitations include heterogeneity across studies and inclusion of both neurologically-intact and non-intact patients.

Conclusion. Considering the similarities in neurological, radiological and functional outcomes between the anterior and posterior approaches, the longer duration and estimated blood loss in the anterior approach should be a point of consideration when selecting the surgical approach undertaken. To advance current evidence, future studies should compare the anterior and posterior approaches in non-intact patients with traumatic thoracolumbar burst fractures.

Level of Evidence: Level III systematic review and meta-analyses 
Key Words: Burst fracture, Thoracolumbar fracture, Anterior approach, Posterior Approach, AO Type A3 \& A4 


\section{Background}

Burst fractures make up 15\% of traumatic thoracolumbar fractures(1). Both anterior and posterior approaches have been utilized in the treatment of these fractures. Surgery is aimed at restoring or maintaining neurological function, correction of deformity or prevention of deterioration. Anterior and posterior approaches have their respective purported advantages and disadvantages when it comes to surgical, radiographical and functional patient outcomes. However, there remains no clear contemporary consensus on the clinical equivalence of these two approaches.

Mechanistically, burst fractures result from a compressive axial load. A burst fracture is defined as a fracture of the vertebral body involving the superior and/or inferior endplate, concomitant with fracture involvement of the cortical bone of the posterior wall of the vertebral body. This 'burst' component can result in bony retropulsion into the spinal canal with potential compression of the cord/conus medullaris/cauda equina and variable degrees of neurological deficit.

The study of traumatic spinal fractures requires clear and reproducible fracture categorization so as to allow generalization of findings. In this review, the authors included only "pure" single level burst fractures without concomitant posterior osteoligamentous, distraction, rotational or translational injuries. There is significant regional variability and no consensus on conservative versus surgical management in the management of burst fractures, especially in patients who are neurologically-intact or with radicular symptoms only(2). The aim of this systematic review and meta-analysis is to compare the surgical, radiological and functional outcomes between anterior and posterior approaches in patients who have sustained a traumatic thoracolumbar burst fracture deemed appropriate for surgical intervention.

\section{Methods}

\section{Search Strategy}

A systematic electronic search of Medline/Pubmed, Web of Science, EMBASE, Google Scholar and the Cochrane Database was performed from the respective databases' date of inception to $30^{\text {th }}$ June 2018. For all databases, the following terms were used either as MeSH terms (Medline/Pubmed, see Figure 1) or key words/topics (all other databases) in the search strategy. Boolean combinations of the terms “Spinal Fractures”, “Spinal Cord Injury”, 
“Thoracic Vertebrae”, “Lumbar Vertebrae” and "Fracture Fixation” were used as MeSH terms. Key words/topics used included boolean combinations of "Burst”, "Burst Fracture”, “Thoracolumbar”, “A3”, “A4”, “Surgery”, “Anterior” and “Posterior”. Titles and/or abstracts of all returned search results were screened by two authors (Tan, Tee). Post-screening, fulltext articles of all potential studies were assessed for final inclusion. The bibliography and citing articles of all included studies were further screened to identify additional eligible articles. This review adheres to the guidelines as stated in the Preferred Reporting Items for Systematic Reviews and Meta-analyses (PRISMA). A protocol does not exist for this review.

\section{$\underline{\text { Selection Criteria }}$}

Inclusion criteria included the following: (1) comparative study design, prospective or retrospective, (2) traumatic thoracolumbar burst-type fracture from T10 to L2, (3) at least six months follow-up, (4) reporting at least one of the following outcomes: neurological function, kyphotic deformity (measured using Cobb angle), postoperative complications, construct failure (defined as any instrumentation fracture/breakage, implant loosening or pullout, regardless of the need for revision surgery), return to theatre, length of stay, estimated blood loss, hospitalization cost, pre- and postoperative pain and functional scores [including visual analogue scale (VAS), Owestry disability index (ODI), Roland Morris Disability Questionnaire (RMDQ)] and ability to return to work. Exclusion criteria included the following: (1) pathologic or osteoporotic fracture, (2) non-burst fractures i.e. end-plate fractures, distraction injuries, translational injuries, rotational injuries, posterior osteoligamentous complex injuries, AO Type A1, A2, B, C fractures, Denis non-burst fractures (i.e. compression, seatbelt-type, fracture-dislocation).

Articles with a combination of different fracture types were included if subgroup analysis was available for the burst fracture group. Of note, both neurologically-intact and neurologically-compromised patients were included. The relatively stringent inclusion and exclusion criteria serves to maintain the homogeneity of the fractures under investigation in terms of their mechanism of injury (i.e. axial compressive loading) and fracture morphology.

\section{Data Extraction and Processing}

Extracted data was entered into a pre-formatted spreadsheet using Microsoft Excel. Data included author, year of publication, study design, patient demographics, operation features (description of procedure, type of decompression, instrumentation), operative outcomes (duration of surgery, estimated blood loss). Radiological outcomes (kyphotic deformity), 
clinical outcomes (neurological function, mortality and morbidity) and patient functional outcomes (e.g. VAS, ODI, RMDQ), rate of return to work were recorded. Morbidity was recorded in terms of overall surgical complication rate (defined as approach-related, infection, or instrumentation-related complication) and construct failure rate. Data was extracted from full text articles, tables or figures by one reviewer (Tan) and accuracy of entered data confirmed by another reviewer (Tee).

\section{$\underline{\text { Assessment of Bias }}$}

Quality of evidence was assessed based on criteria published by the Cochrane handbook for systematic review of interventions(3). Entries assessed for risk of bias was rated as "Yes", "No" or "Unclear. For non-randomized studies, the Newcastle-Ottawa Quality Assessment Scale(4) was used. Any interobserver disagreement (Tan, Tee) was resolved by consensus.

\section{Qualitative Analysis and Meta-Analysis of Outcomes}

In this review, quantitative synthesis of effect sizes was undertaken for outcomes suitable for meta-analysis. Outcome variables unsuitable for meta-analysis is qualitatively analyzed and described.

For meta-analysis, risk ratio (RR) for binary outcomes (construct failure rate, rate of return to work) and mean differences (MD) for continuous outcomes (postoperative angular kyphosis, length of stay, duration of surgery, estimated blood loss, total hospital charges) were used as summary statistics. The effect size and confidence intervals (95\% CIs) were reported using Forest plots. The $\mathrm{I}^{2}$ statistic was used to estimate the percentage of error due to between-study heterogeneity, with values more than $50 \%$ representing substantial heterogeneity. In cases of zero events for binary outcomes, a continuity correction of 0.5 was applied as suggested by the Cochrane handbook. The range rule(5) for standard deviation [Standard deviation=(Maximum - Minimum] $) / 4$ ] was used to estimate the standard deviation when required. All statistical analysis was conducted with an open source software (OpenMetaAnalyst, Providence, Rhode Island).

\section{Results}

\section{$\underline{\text { Literature Search }}$}

The initial systematic search yielded 4015 articles, of which 40 were eligible for full-text review. 34 articles were excluded after full-text review. Thus, six articles(6-11) were 
identified as suitable for final inclusion. Figure 1 summarizes the results of the initial literature search and reasons for exclusion post full text review.

\section{$\underline{\text { Study Characteristics }}$}

Of the six included studies, two were randomized controlled trials(8, 10), one(9) was a prospective non-randomized study, and three $(6,7,11)$ were retrospective cohort studies. The number of subjects in each study ranged from 25 to 94 (Median: 44). Duration of follow up ranged from 12 to 718 months. Table 1 summarizes the study design, patient demographics and fracture levels included in the six included studies.

\section{$\underline{\text { Results of Qualitative Analysis }}$}

1) Description and rationale of surgical approach

All six studies had some form of description regarding the anterior and posterior surgeries performed. Two articles $(6,11)$ did not describe the rationale for performing anterior versus posterior approach surgery. Surgeon preference and availability of prosthesis determined the selected approach in two studies $(7,9)$, whilst surgical approach in two $(8,10)$ articles were decided by randomization (RCT).

For the anterior approach, all surgeries were performed with patients in the right lateral decubitus position (left side up). Subtotal corpectomies were performed in all studies, with variable reporting on the degree of direct spinal decompression. Fixation was achieved with combinations of cages, plates with screws, and/or screws with rods. Table 2 summarizes the positioning, method of decompression, fixation and fusion for the anterior approaches.

For the posterior approach, all surgeries were performed in the prone position. Direct decompression was achieved with either with laminectomy or transpedicular/facetal decompression. In two studies $(8,11)$, decompression was exclusively achieved in an indirect fashion via annulotaxis/ligamentotaxis. Fixation was attained most commonly with pedicle screws, transverse process hooks, and rod fixation. Bony fusion was augmented most commonly with iliac crest bone graft or autologous bone grafting. Table 3 summarize the positioning, method of decompression, fixation and fusion for the posterior approaches.

2) Neurological outcome 
Three articles $(6,7,9)$ included patients who were both neurologically intact and non-intact. One article(8) included only neurologically-intact patients, whilst two studies $(10,11)$ did not specify the neurological status.

Only two articles(6, 7) had information on pre and postoperative neurological outcomes. Hitchon et.al(6) transmuted categorical Frankel grades into interval data and demonstrated no significant difference between anterior and posterior approaches in preserving/improving neurological function in patients. Surgery regardless of approach resulted in equivalent, and significant improvement in non-intact patients compared to their preoperative Frankel grade. Danisa et.al(7) similarly reported improvements of zero, one or two Frankel grades in nonintact patients undergoing either anterior or posterior approach surgery. All Frankel E patients remained neurologically intact and there was no neurological deterioration in all patients.

3) Postoperative mortality and postoperative overall surgical complication rate

There was no perioperative mortality reported in all six articles. Three articles(7-9) reported data from which overall surgical complication rate could be determined. Besides construct failure rate, definitions of what consisted a complication was inconsistent and not welldefined and thus unsuitable for meta-analysis. Danisa et.al(7) reported an overall surgical complication rate of $25.0 \%$ (4 complications in 16 patients: two pneumothoraces, one painful iliac crest bone graft site, one fractured Kaneda screw) in the anterior group compared to 11.1\% (3 complications in 27 patients: two deep wound infections, one pseudarthrosis) in the posterior group (no comparative statistical analysis). Stancic et. al.(9) reported an overall surgical complication rate of 23.1\% (3 complications in 13 patients: one with haemothoraces, two with painful iliac crest bone graft site) in the anterior group compared to $8.3 \%$ (1 complication in 12 patients: one superficial wound infection) in the posterior group (no comparative statistical analysis).

Wood et.al(8), in a randomized controlled trial, reported an overall surgical complication rate of 5.0\% (1 complication in 20 patients: one pseudarthrosis) in the anterior group compared to 50.0\% (9 of 18 patients: two wound dehiscence, one wound seroma, two instrumentation failure, two instrumentation breakage, one wound infection, one pseudarthrosis) in the posterior group.

4) Postoperative revision/supplementation of instrumentation rate 
Two articles had information on the rate of return to theatre for revision of instrumentation. Hitchon et.al.(6) reported a revision rate of 5.3\% (two of 38 patients; one with allograft migration into spinal canal, one with early postoperative kyphotic angulation) for the anterior group and 12.0\% (three of 25 patients; one with postoperative kyphosis and claw-hook disengagement, one with malpositioning of pedicle screws, one unspecified "construct failure”) in the posterior group. There was no significant difference between groups in terms of instrumentation revision rate. Danisa et.al reported a revision rate of $0 \%$ for the anterior group and 3.7\% (one of 27 patients with back pain and pseudarthrosis) for the posterior group.

\section{$\underline{\text { Results of Meta-Analysis }}$}

The following outcome variables were suitable for meta-analysis.

\section{1) Duration of surgery (Figure 2)}

Five studies(6-9, 11) had sufficient data on operative duration. The pooled mean operative time for anterior approach was 285 min (Range: 176 to 438 mins) compared with 203 min (Range: 94 to $413 \mathrm{~min}$ ) for the posterior approach. The anterior approach took a significantly longer duration compared to the posterior approach (Mean difference (MD) $+81.68,95 \%$ CI 39.20 to $124.16, \mathrm{P}<0.001)$.

2) Estimated blood loss (Figure 3)

Four studies $(7-9,11)$ had sufficient data on estimated blood loss at surgery. The pooled estimated blood loss for anterior approach was $970 \mathrm{ml}$ (Range: 255 to $1878 \mathrm{ml}$ ) compared with $558 \mathrm{ml}$ (Range: 117 to $1103 \mathrm{ml}$ ) for the posterior approach. The anterior approach was associated with an increased blood loss as compared to the posterior approach (MD +426.27, 95\% CI 119.84 to $732.70, \mathrm{P}=0.006)$.

3) Length of stay (Figure 4)

Four studies(6-9) had sufficient data on length of stay in hospital. The pooled length of stay for the anterior approach was 14.6 days (Range: 7.2 to 18.6 days) compared to 12.7 days (Range: 10.0 to 19.0 days) for the posterior approach. There was no significant difference between the anterior and posterior approach with regards to length of stay (MD +1.30, 95\% CI -3.71 to $6.30, \mathrm{P}=0.612$ ).

4) Late postoperative kyphotic angle (Figure 5) 
Four studies $(6-8,11)$ had sufficient data on the postoperative kyphotic (Cobb) angle measured during extended follow up. The pooled postoperative kyphotic angle for the anterior approach was 7.6 degrees (Range: 4.5 to 10.0 degrees) compared with 9.2 degrees (Range: 4.6 to 12.5 degrees) for the posterior approach. There was no significant difference between the anterior and posterior approach with regards to the late postoperative kyphotic angle (MD -1.26, 95\% CI -3.84 to 1.32, $\mathrm{P}=0.338)$.

\section{5) Construct failure rate (Figure 6)}

Five studies(6-10) had sufficient data on construct failure rate. The pooled construct failure rate for the anterior approach was 3.7\% (4 of 109 cases) compared with 11.4\% (12 of 105) for the posterior approach. There was a trend towards increased failure with the posterior approach, but no statistically significant difference between the anterior and posterior approach with regards to construct failure rate (RR 0.39, 95\% CI 0.14 to $1.07, \mathrm{P}=0.066$ ).

6) Return to work (Figure 7)

Three studies(8-10) had sufficient data on return to work post-surgery. The pooled return to work rate for the anterior approach was 80.8\% (42 of 52 cases) compared with $84.0 \%$ (42 of 50 cases) for the posterior approach. There was no significant difference between the anterior and posterior approach with regards to the rate of returning to work (RR 0.97, 95\% CI 0.81 to 1.16, $\mathrm{P}=0.73)$.

7) Total hospital charges (Figure 8)

Three studies(6, 7, 9) had sufficient data on total hospital charges. The pooled total hospital charge for the anterior approach was \$51917 (Range: \$2700 to \$89090) compared with \$42518 (Range: \$2250 to \$80000) or the posterior approach. There was no significant difference between the anterior and posterior approach with regards to total hospital charges ( $\mathrm{MD}+8583.06,95 \%$ CI -4296.25 to $21462.37, \mathrm{P}=0.191)$.

\section{$\underline{\text { Evaluation of bias }}$}

Risk of bias for non-randomized studies evaluated with the Newcastle-Ottawa scale was found to be high, mostly due to the lack of control for demographic variables between cohorts (Table 4, “Comparability of cohorts”). Table 5 demonstrates risk of bias assessment for the randomized controlled trials in this review. Adhering to the recommendations of the Cochrane handbook(3), domains and criteria adjudged as being critical for the purposes of 
this review include points 1 (method of randomization), 2 (concealment of treatment allocation), 5 (blinding of outcome assessor), and 9 (similarity of important prognostic indicators between groups) in Table 5 . Within individual studies, Wood et.al(8) demonstrated a high risk of bias, whilst Wang et.al.(10) demonstrated a low risk of bias.

\section{$\underline{\text { Discussion }}$}

Surgical corridors in the management of thoracolumbar burst fractures include anterior, posterior, or combined anterior-posterior approaches. This article looks specifically at single level burst-only fractures deemed appropriate for surgical management. In general, surgical management is aimed at 1) preserving neurological function or reversing neurological dysfunction, 2) correction of deformity, and 3) correcting instability. The ultimate goal, however, is to attempt to return the injured patient to his pre-morbid level of activity and function.

Only two articles $(6,7)$ had information on pre and postoperative neurological function. There was one instance of neurological deterioration (from Frankel B to A) in Hitchon et.al's(6) posterior group but this occurred whilst the patient was awaiting surgery. Otherwise, there was no neurological deterioration in either study, and all intact patients remained intact postoperatively. Non-intact patients either remained within their Frankel grade, or improved by one to two grades. One reason the anterior approach is favoured by some surgeons is the ability to directly decompress the central canal via a subtotal corpectomy and direct removal of fracture fragments from the posterior vertebral body. Fracture fragment removal is possible from a posterolateral approach but is a relatively more circuitous route and requires increased exposure e.g. via a transpedicular corridor. In this review, canal decompression in the posterior group was mainly achieved via laminectomy and indirectly by annulotaxis/ligamentotaxis, where the retropulsed burst component will not be directly removed. Nonetheless, the current evidence will suggest that both anterior and posterior approaches are adequate in preventing neurological decline and potentially improving neurological function.

Regarding deformity correction, there was no difference between the anterior and posterior approaches in the degree of kyphotic deformity at long term follow up, as measured by the Cobb angle. Compared to conservative management, surgical fixation results in reduced kyphotic deformity in the long term, and both anterior or posterior approaches are equivalent in achieving this outcome. However, it is also important to note that reduced kyphotic 
deformity does not necessarily lead to improved patient outcomes or reduced back pain on long-term follow up(12).

Severe mechanical back pain preventing mobilization is an indication for surgical fixation. However, surgery for the sole purpose of correcting instability is controversial in traumatic thoracolumbar burst fractures, especially in a neurologically-intact patient without significant kyphotic deformity (<30 to 35 degrees). This is because a true burst-only fracture is an inherently "stable" fracture(13). From a morphological and mechanistic standpoint, a burst fracture results from an axial compressive force resulting in fracture of the superior and (complete burst)/or (incomplete burst) inferior endplate, concomitant with fracture involvement of the cortical margin of the posterior vertebral body wall. There is no posterior element involvement, no posterior ligamentous complex involvement, and no distraction, translational or rotational injury. Fracture classification systems provide a common language for surgeons to describe fracture types and guide treatment decisions. Denis et.al's(14) wellknown system clearly defines burst fractures (Type A - E) as a separate major fracture type. The thoracolumbar injury classification system (TLICS)(15) will advocate for non-surgical management in a neurologically-intact patient with a burst (i.e. compression) fracture (TLICS score $=2)$. In the AO thoracolumbar fracture classification system(16), a burst fracture is an A3 or A4 fracture. A recent meta-analysis by Rometsch et.al(17) concluded that there was no difference in pain and functional scores between surgery and conservative (orthosis, no orthosis) management in intact patients with A3 or A4 thoracolumbar fractures. Further, a randomized controlled trial with long-term follow up conducted by Bailey et.al(13), compared orthotic versus non-orthotic (mobilization as tolerated) treatment in neurologicallyintact AO Type A3 fractures. In this trial, there was no difference in the primary outcome (Roland-Morris Disability Questionnaire) and secondary outcomes (pain, Short-Form 36, patient satisfaction) up to two years post-injury. The current body of evidence will suggest that in the neurologically-intact patient with an AO Type A3 or A4 fracture, conservative management is appropriate and equivalent to surgical management. It is unknown if A4 fractures can be successfully managed without an orthosis.

From the results of the meta-analysis, anterior approach surgery was found to be significantly longer in duration and resulted in increased estimated blood loss as compared to the posterior approach. However, this did not translate into increased length of stay or total hospital costs between the two groups. Both approaches were also equivalent in their ability to return the patient to work postoperatively. 
The likelihood of complication is a factor in the consideration of which surgical approach to undertake. There was a non-significant trend towards a higher construct failure rate in the posterior as compared to the anterior approach. Regarding overall surgical complication rates, Danisa et.al(7) and Stancic et.al(9) reported relatively similar rates for the anterior and posterior approaches at $23.1 \%$ to $25.0 \%$ for the anterior group, and $8.3 \%$ to $11.1 \%$ for the posterior group. Haemopneumothoraces in the anterior group, and wound infections in the posterior group are the two most common approach-related morbidities. Pain from iliac crest bone graft donor sites was also often reported as a complicated associated with the anterior approach. As such, an option to negate this morbidity might be to utilize other bone graft options such as autologous bone graft or synthetic bone graft substitutes.

The overall surgical complication rates reported by Wood et.al(8) represent a deviation from the above rates (5.0\% in the anterior group, and $50.0 \%$ in the posterior group), with an exceedingly high complication rate in the posterior group. In this study, the posterior approach was performed via three to four-level fixation with cephalad claw hook fixation, and caudad pedicle screws and infra-laminar hooks with posterolateral iliac crest bone grafting. Decompression was not performed. There was a high rate of construct failure (two “instrumentation failure”, two instrumentation breakage, one pseudarthrosis) that surpasses most rates reported in the literature even for AO Type B and C thoracolumbar fractures(18, 19). Further, a third of patients (six of 18 patients) in the posterior group required instrumentation removal secondary to instrumentation-related pain. The article's authors did not postulate as to the reason for this high rate of instrumentation removal. The outlier results from this article should be interpreted with caution. Removal of the data from this study dilutes and diminishes the trend towards increased construct failure for the posterior approach (data not shown).

With regard to the rate of instrumentation revision/supplementation, the limited qualitative evidence from two articles $(7,20)$ suggest that there is no difference in the rate of instrumentation revision between the anterior or posterior approaches. From this point of view, individual surgeon preference can be used to decide upon the approach taken. This meta-analysis confirms the longer duration of surgery and estimated blood loss associated with the anterior approach. The former could be due to unfamiliarity and the often narrower surgical corridor when utilizing the anterior approach. Considering the similarities in neurological, radiological and functional outcomes between the anterior and posterior 
approaches, the longer duration and estimated blood loss in the anterior approach should be a point of consideration when selecting the surgical approach undertaken.

\section{$\underline{\text { Strengths and Limitations }}$}

To the authors' knowledge, this is the first systematic review on traumatic thoracolumbar fractures that focuses specifically on true burst fractures only. Previous review articles have included fractures of differing morphologies and pathologies(21, 22). The present review, by focusing on burst fractures only, improves the generalizability of the recommendations made. A comprehensive evaluation of treatment outcomes is made possible by both qualitative and quantitative meta-analysis of the results. Adherence to PRISMA guidelines, and risk of bias evaluation with standardized methods (Cochrane handbook, Newcastle-Ottawa scale) further strengthens the quality of this review.

One limitation of this review is the inclusion of patients who are both neurologically intact and non-intact. There are no studies in the literature that have specifically investigated the anterior versus posterior approach in non-intact patients with burst fractures. There is increasing evidence that in neurologically-intact patients with true traumatic thoracolumbar burst fractures, conservative management is at least equivalent to surgical management and negates exposure to the risk of surgery(17). What is unknown is the comparative efficacy of anterior versus posterior approaches in the management of the non-intact patient with true thoracolumbar burst fractures. Further research should be performed in this area.

Most of the studies included in this systematic review have a high risk of intra-study bias, as shown in Tables 4 and 5. Thus, this will lower the strength of the results and recommendations found in the present review. Further, few studies had robust reporting of patient-reported outcomes measures and as such, meta-analysis on these important measures were not feasible. It is not possible to draw solid conclusions regarding the relative benefits of the anterior versus posterior approach in the important domains of patient functional outcomes and satisfaction.

\section{Conclusions}

Besides longer operative duration and increased estimated blood loss in the anterior approach, the limited available evidence suggests no differences between the anterior and posterior approaches in the clinical, radiological and functional outcomes included in this 
review. There is a non-significant trend towards increased construct failure rate in the posterior group. To advance current evidence, future studies should compare the anterior and posterior approaches in non-intact patients with traumatic thoracolumbar burst fractures. These studies should ideally be large-scale, multi-center, randomized controlled trials. 


\section{Authorship}

TT and JT designed the study, acquired and analyzed the data. All authors contributed to interpreting the data, drafting and critically revising the manuscript.

\section{Disclosure}

The authors declare no conflicts of interest 


\section{Bibliography}

1. Esses SI, Botsford DJ, Kostuik JP. Evaluation of surgical treatment for burst fractures. Spine (Phila Pa 1976). 1990;15(7):667-73.

2. Vaccaro AR, Schroeder GD, Kepler CK, Cumhur Oner F, Vialle LR, Kandziora F, Koerner JD, Kurd MF, Reinhold M, Schnake KJ, et al. The surgical algorithm for the AOSpine thoracolumbar spine injury classification system. Eur Spine J. 2016;25(4):1087-94.

3. Higgins GS. Cochrane Handbook for Systematic Reviews of Interventions: The Cochrane Collaboration; March 2011.

4. Stang A. Critical evaluation of the Newcastle-Ottawa scale for the assessment of the quality of nonrandomized studies in meta-analyses. Eur J Epidemiol. 2010;25(9):603-5.

5. Hozo SP, Djulbegovic B, Hozo I. Estimating the mean and variance from the median, range, and the size of a sample. BMC Med Res Methodol. 2005;5:13.

6. Hitchon PW, Torner J, Eichholz KM, Beeler SN. Comparison of anterolateral and posterior approaches in the management of thoracolumbar burst fractures. Journal of neurosurgery Spine. $2006 ; 5(2): 117-25$.

7. Danisa OA, Shaffrey $\mathrm{Cl}$, Jane JA, Whitehill R, Wang GJ, Szabo TA, Hansen CA, Shaffrey ME, Chan DP. Surgical approaches for the correction of unstable thoracolumbar burst fractures: a retrospective analysis of treatment outcomes. Journal of neurosurgery. 1995;83(6):977-83.

8. Wood KB, Bohn D, Mehbod A. Anterior versus posterior treatment of stable thoracolumbar burst fractures without neurologic deficit - A prospective, randomized study. Journal of Spinal Disorders \& Techniques. 2005;18:S15-S23.

9. Stancic MF, Gregorovic E, Nozica E, Penezic L. Anterior decompression and fixation versus posterior reposition and semirigid fixation in the treatment of unstable burst thoracolumbar fracture: prospective clinical trial. Croatian medical journal. 2001;42(1):49-53.

10. Wang JF, Liu P. Analysis of surgical approaches for unstable thoracolumbar burst fracture: minimum of five year follow-up. Journal of the Pakistan Medical Association. 2015;65(2):201-5. 
11. Wu H, Wang C-x, Gu C-y, Zhang Z-y, Tong S, Yan H-d, Wang J-c. Comparison of three different surgical approaches for treatment of thoracolumbar burst fracture. Chinese journal of traumatology = Zhonghua chuang shang za zhi. 2013;16(1):31-5.

12. Sadatsune DA, Costa PP, Caffaro MF, Umeta RS, Meves R, Avanzi O. THORACOLUMBAR BURST FRACTURE: CORRELATION BETWEEN KYPHOSIS AND FUNCTION AFTER SURGICAL TREATMENT. Rev Bras Ortop. 2012;47(4):474-8.

13. Bailey CS, Urquhart JC, Dvorak MF, Nadeau M, Boyd MC, Thomas KC, Kwon BK, Gurr KR, Bailey SI, Fisher CG. Orthosis versus no orthosis for the treatment of thoracolumbar burst fractures without neurologic injury: a multicenter prospective randomized equivalence trial. The spine journal : official journal of the North American Spine Society. 2014;14(11):2557-64.

14. Denis $F$. The three column spine and its significance in the classification of acute thoracolumbar spinal injuries. Spine (Phila Pa 1976). 1983;8(8):817-31.

15. Lee JY, Vaccaro AR, Lim MR, Oner FC, Hulbert RJ, Hedlund R, Fehlings MG, Arnold P, Harrop J, Bono $\mathrm{CM}$, et al. Thoracolumbar injury classification and severity score: a new paradigm for the treatment of thoracolumbar spine trauma. J Orthop Sci. 2005;10(6):671-5.

16. Vaccaro AR, Oner C, Kepler CK, Dvorak M, Schnake K, Bellabarba C, Reinhold M, Aarabi B, Kandziora F, Chapman J, et al. AOSpine thoracolumbar spine injury classification system: fracture description, neurological status, and key modifiers. Spine (Phila Pa 1976). 2013;38(23):2028-37. 17. Rometsch E, Spruit M, Hartl R, McGuire RA, Gallo-Kopf BS, Kalampoki V, Kandziora F. Does Operative or Nonoperative Treatment Achieve Better Results in A3 and A4 Spinal Fractures Without Neurological Deficit?: Systematic Literature Review With Meta-Analysis. Global spine journal. 2017;7(4):350-72.

18. Grossbach AJ, Dahdaleh NS, Abel TJ, Woods GD, Dlouhy BJ, Hitchon PW. Flexion-distraction injuries of the thoracolumbar spine: open fusion versus percutaneous pedicle screw fixation. Neurosurgical Focus. 2013;35(2). 
19. Jiang XZ, Tian W, Liu B, Li Q, Zhang GL, Hu L, Li ZY, He D. Comparison of a Paraspinal Approach with a Percutaneous Approach in the Treatment of Thoracolumbar Burst Fractures with Posterior Ligamentous Complex Injury: a Prospective Randomized Controlled Trial. Journal of International Medical Research. 2012;40(4):1343-56.

20. Wang L, Li JJ, Wang H, Yang Q, Lv DC, Zhang WG, Tang K, Shang LM, Jiang CM, Wu CM, et al. Posterior short segment pedicle screw fixation and TLIF for the treatment of unstable thoracolumbar/lumbar fracture. Bmc Musculoskeletal Disorders. 2014;15.

21. Zhu QC, Shi FC, Cai WH, Bai JL, Fan J, Yang HL. Comparison of Anterior Versus Posterior Approach in the Treatment of Thoracolumbar Fractures: A Systematic Review. International Surgery. 2015;100(6):1124-33.

22. Xu GJ, Li ZJ, Ma JX, Zhang T, Fu X, Ma XL. Anterior versus posterior approach for treatment of thoracolumbar burst fractures: a meta-analysis. European Spine Journal. 2013;22(10):2176-83. 
Figure 1. PRISMA Flow Diagram of Study Inclusion
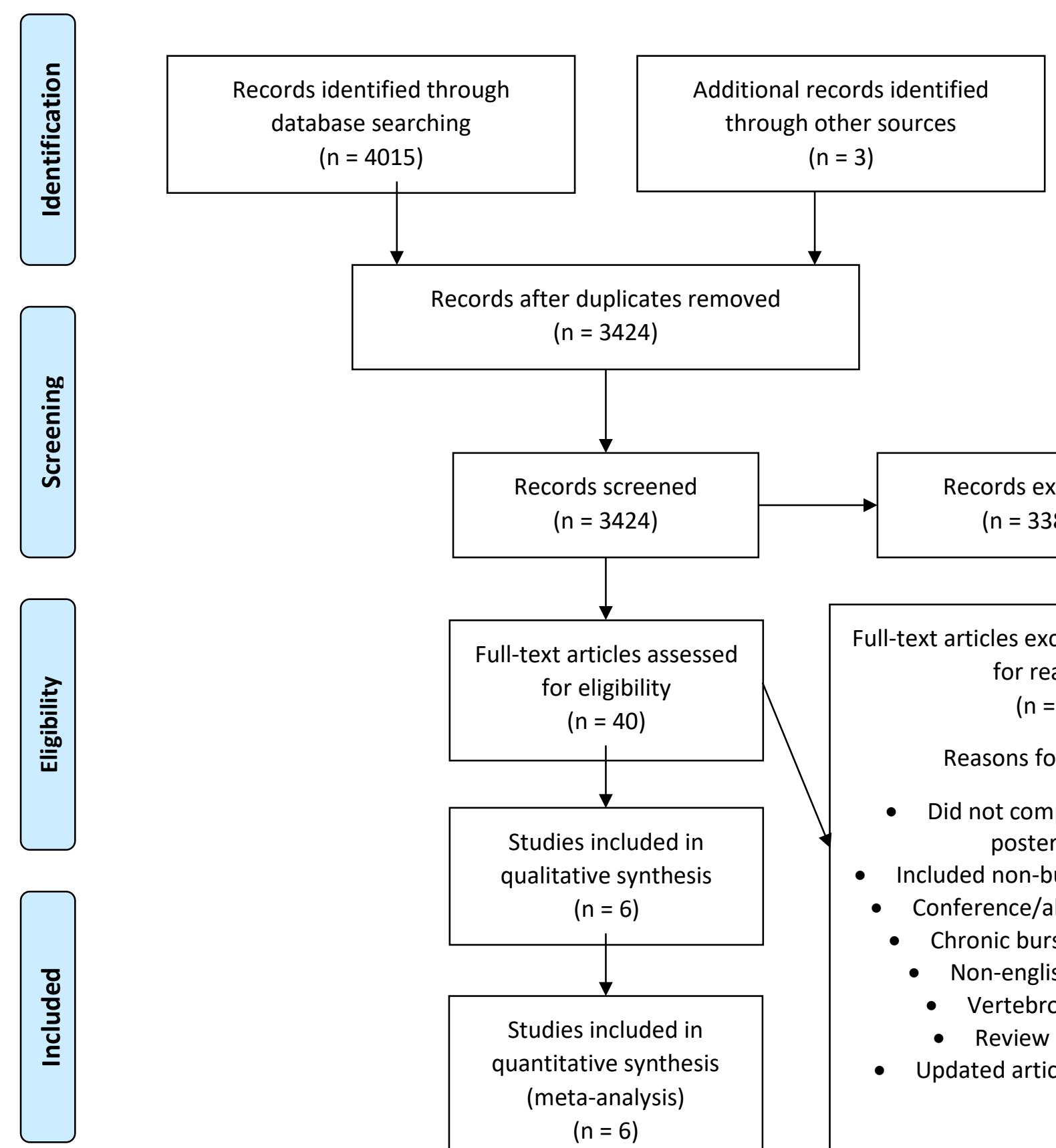

Records after duplicates removed

$(n=3424)$
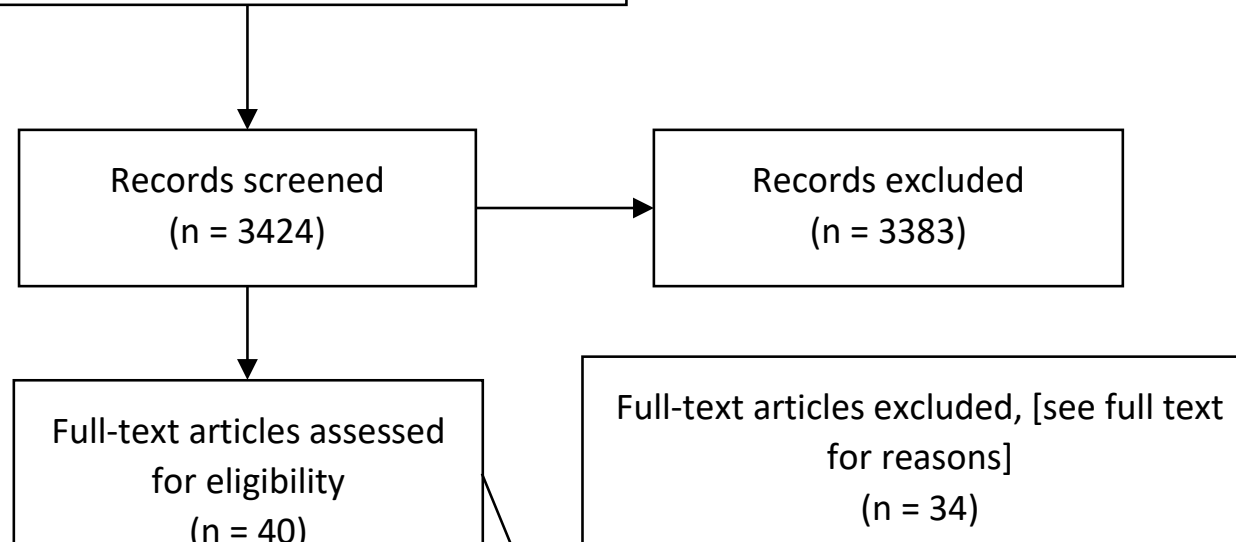

Reasons for exclusion

- Did not compare anterior vs.

Studies included in qualitative synthesis posterior: $\mathrm{n}=16$

- Included non-burst fractures: $\mathrm{n}=9$

- Conference/abstract only: $n=2$

- Chronic burst fracture: $\mathrm{n}=2$

- Non-english article: $\mathrm{n}=2$

- Vertebroplasty: $\mathrm{n}=1$

Studies included in quantitative synthesis

(meta-analysis)

- Review artcle: $\mathrm{n}=1$

- Updated article available: $\mathrm{n}=1$

$$
(n=6)
$$




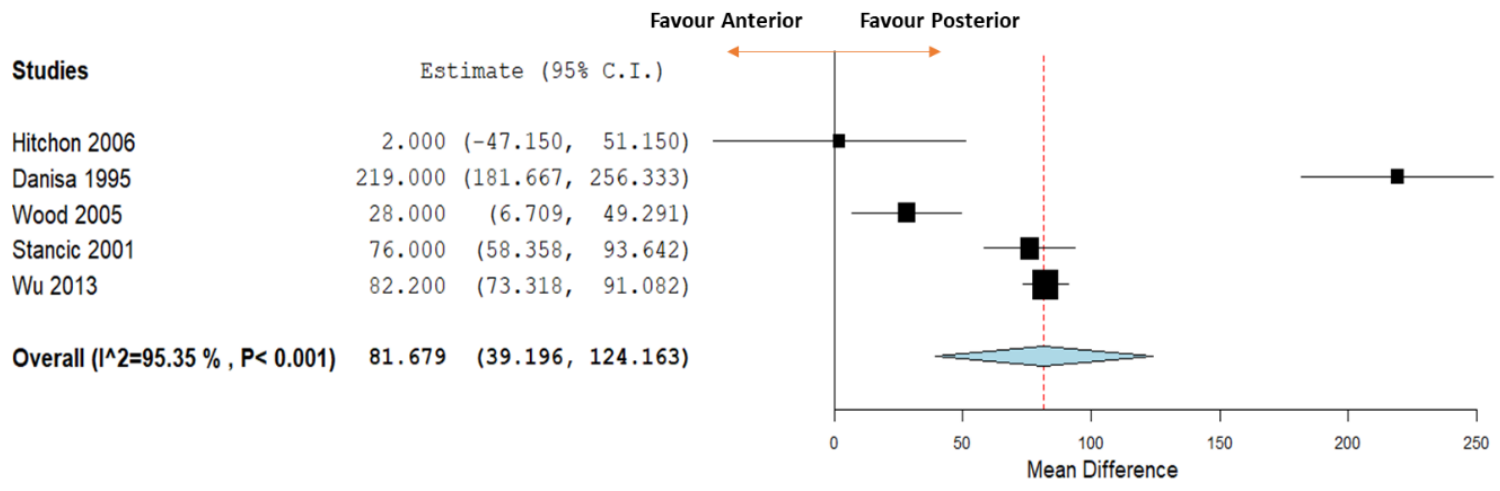

Figure 2. Meta-analysis of duration of surgery. 


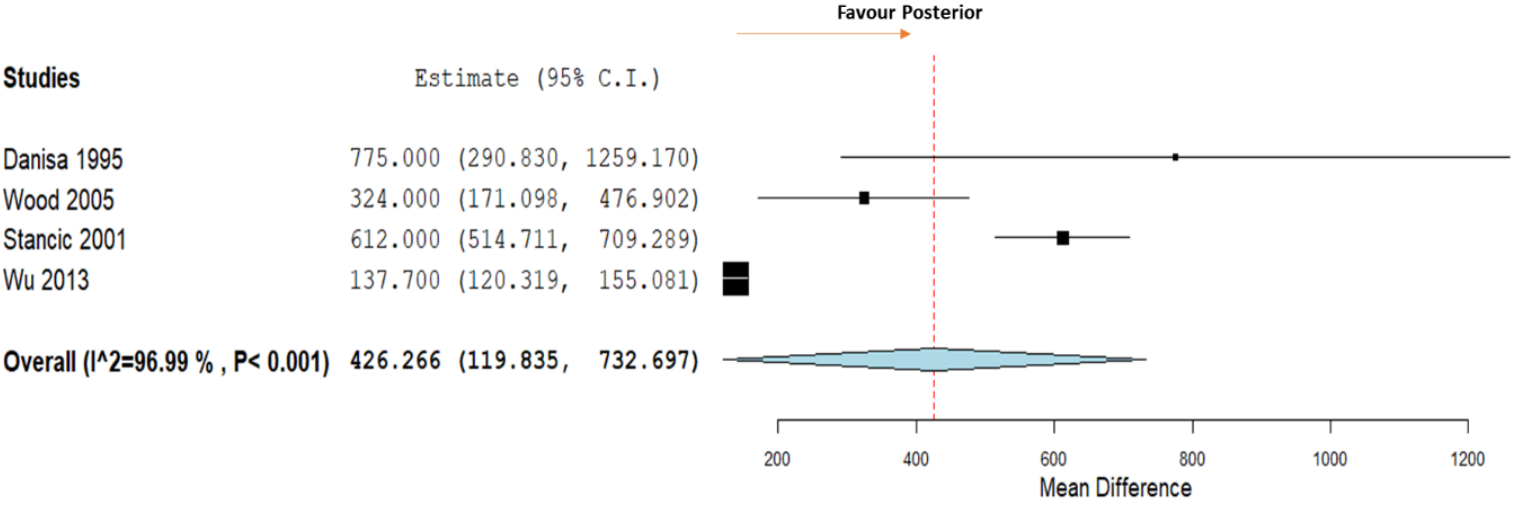

Figure 3. Meta-analysis of estimated blood loss 


\begin{tabular}{|c|c|}
\hline Studies & Estimate (95\% C.I.) \\
\hline Hitchon 2006 & $-2.000 \quad(-7.445$ \\
\hline Danisa 1995 & $3.000(-0.187,6.187)$ \\
\hline Wood 2005 & $-2.900 \quad(-5.386,-0.414)$ \\
\hline Stancic 2001 & $6.400 \quad(4.302,8.498)$ \\
\hline Overall $\left(I^{\wedge} 2=91.19 \%, P<0.001\right)$ & $1.296(-3.707,6.299)$ \\
\hline
\end{tabular}

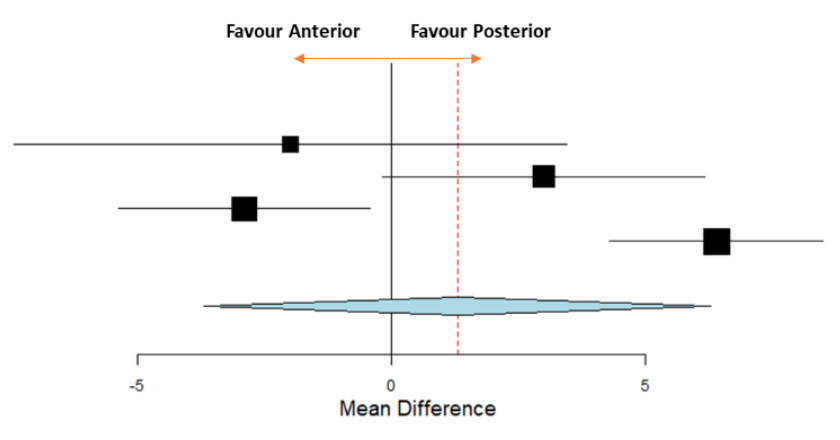

Figure 4. Meta-analysis of length of stay 


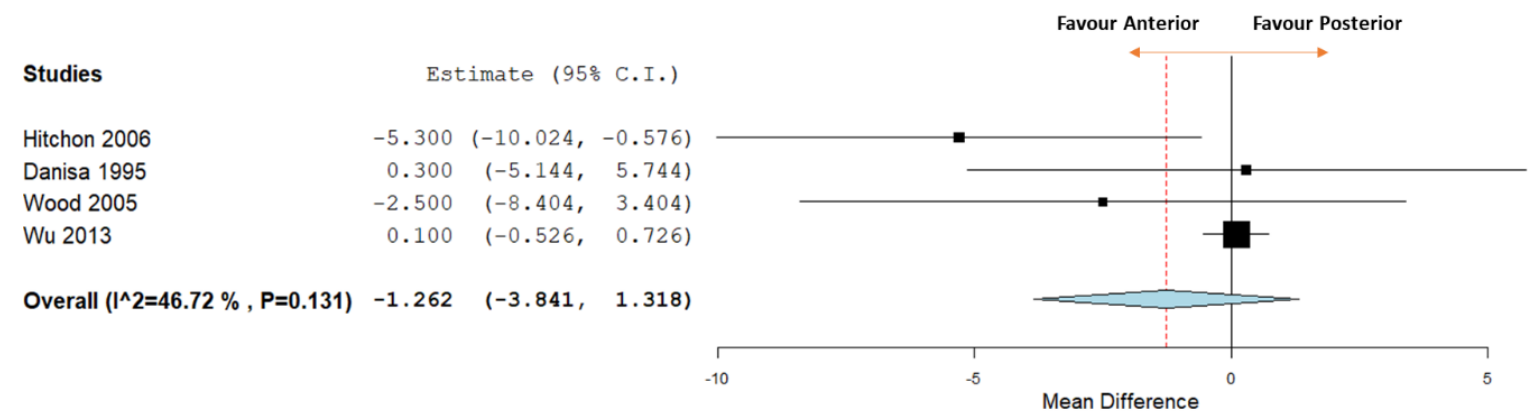

Figure 5. Meta-analysis of late postoperative kyphotic angle 


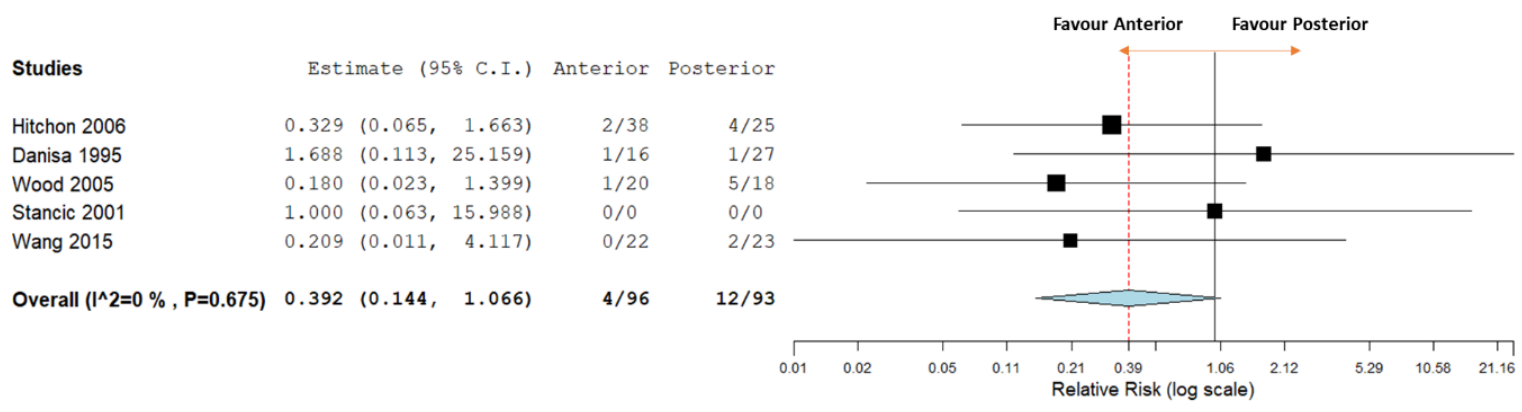

Figure 6. Meta-analysis of construct failure rate 


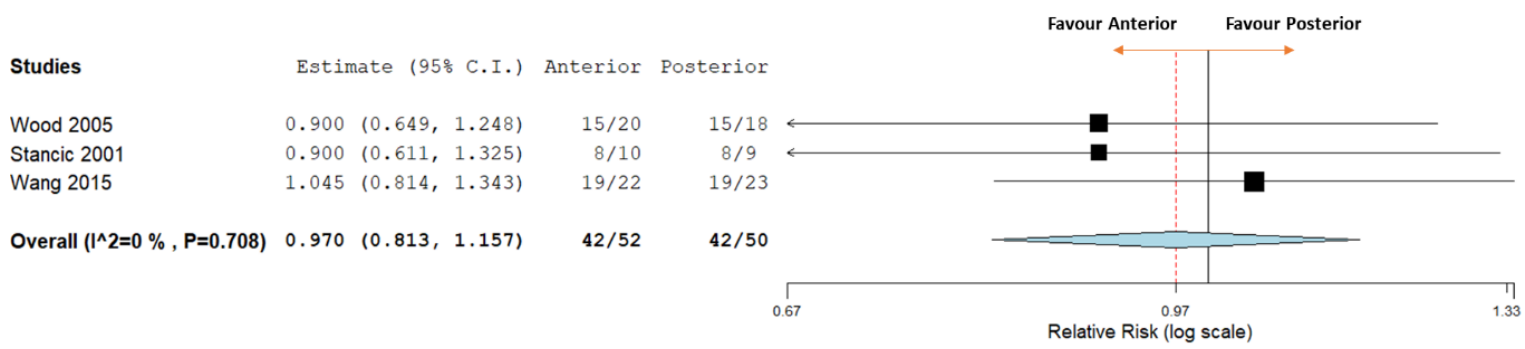

Figure 7. Meta-analysis of return to work rate 


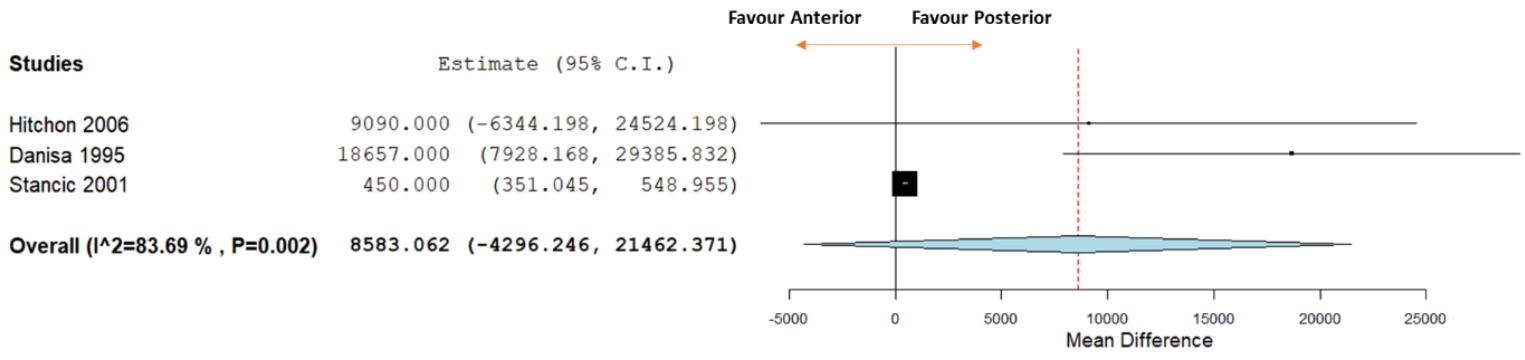

Figure 8. Meta-analysis of total hospital charges 
Table 1. Study design and patient demographics of included studies, fracture levels, method used for classifying burst fractures

\begin{tabular}{|l|l|l|l|l|l|l|l|l|}
\hline $\begin{array}{l}\text { Author, } \\
\text { year }\end{array}$ & $\begin{array}{l}\text { Study } \\
\text { Design }\end{array}$ & $\begin{array}{l}\text { No. of } \\
\text { patients }\end{array}$ & $\begin{array}{l}\text { N } \\
\text { (Ant. } \\
\text { group) }\end{array}$ & $\begin{array}{l}\text { N } \\
\text { (Post. } \\
\text { group) }\end{array}$ & $\begin{array}{l}\text { Age Ant. } \\
\text { group/ } \\
\text { Yrs } \\
\text { Mean } \\
\text { (Range) }\end{array}$ & $\begin{array}{l}\text { Age } \\
\text { (Post. } \\
\text { Group)/ } \\
\text { Yrs } \\
\text { Mean } \\
\text { (Range) }\end{array}$ & $\begin{array}{l}\text { Levels } \\
\text { Include } \\
\text { d }\end{array}$ & $\begin{array}{l}\text { Male } \\
\text { Gende } \\
\text { r/\% }\end{array}$ \\
\hline $\begin{array}{l}\text { Hitcho } \\
\text { n, 2006 }\end{array}$ & $\begin{array}{l}\text { Retrospecti } \\
\text { ve cohort }\end{array}$ & 63 & 38 & 25 & $\begin{array}{l}45(18- \\
70)\end{array}$ & $\begin{array}{l}42(22- \\
64)\end{array}$ & $\begin{array}{l}\text { T11- } \\
\text { L2 }\end{array}$ & $71.4 \%$ \\
\hline $\begin{array}{l}\text { Danisa, } \\
1995\end{array}$ & $\begin{array}{l}\text { Retrospecti } \\
\text { ve cohort }\end{array}$ & 43 & 16 & 27 & $\begin{array}{l}35.4(19- \\
62)\end{array}$ & $\begin{array}{l}37.7(19- \\
75)\end{array}$ & $\begin{array}{l}\text { T12- } \\
\text { L2 }\end{array}$ & $69.8 \%$ \\
\hline $\begin{array}{l}\text { Wood, } \\
2005\end{array}$ & $\begin{array}{l}\text { RCT } \\
\text { SCT }\end{array}$ & 38 & 20 & 18 & $\begin{array}{l}39(18- \\
56)\end{array}$ & $\begin{array}{l}42(19- \\
68)\end{array}$ & $\begin{array}{l}\text { T10 }- \\
\text { L2 }\end{array}$ & $65.8 \%$ \\
\hline $\begin{array}{l}\text { Stancic, } \\
2001\end{array}$ & $\begin{array}{l}\text { Prospective, } \\
\text { non- } \\
\text { randomized } \\
\text { trial }\end{array}$ & 25 & 13 & 12 & $\begin{array}{l}36(18- \\
53)\end{array}$ & $\begin{array}{l}35(16- \\
60)\end{array}$ & $\begin{array}{l}\text { T12- } \\
\text { L2 }\end{array}$ & $60.0 \%$ \\
\hline $\begin{array}{l}\text { Wang, } \\
2015\end{array}$ & RCT & 45 & 22 & 23 & 37.2 & 40.5 & $\begin{array}{l}\text { T12 }- \\
\text { L2 }\end{array}$ & $64.4 \%$ \\
\hline $\begin{array}{l}\text { Wu, } \\
2013\end{array}$ & $\begin{array}{l}\text { Retrospecti } \\
\text { ve cohort }\end{array}$ & 94 & 24 & 70 & N.R. & N.R. & N.R. & $59.6 \%$ \\
\hline
\end{tabular}

Ant, Anterior; Post, Posterior; RCT, Randomized controlled trial; N.R., Not recorded. 
Table 2. Positioning, method of decompression, fixation and fusion for anterior approach

\begin{tabular}{|c|c|c|c|c|}
\hline & \multicolumn{4}{|c|}{ Anterior } \\
\hline Author/Year & Position & Decompression & Fixation & $\begin{array}{l}\text { Supplemental } \\
\text { fusion }\end{array}$ \\
\hline $\begin{array}{l}\text { Hitchon } \\
\text { /2006 }\end{array}$ & $\begin{array}{l}\text { Right } \\
\text { lateral } \\
\text { decubitus }\end{array}$ & N.R. & $\begin{array}{l}\text { - Stackable CFC } \\
\text { cage }(n=17) \\
\text { - Allograft }(n=15) \\
\text { - Titanium cylinder } \\
(n=2) \\
\text { - Dual rods and } \\
\text { screws ( } n=31) \\
\text { - Plates and screws } \\
(n=7)\end{array}$ & $\begin{array}{l}\text { - Femoral } \\
\text { allografts } \\
\text { - Synthetic } \\
\text { anterior strut } \\
\text { grafts } \\
\text { - Autologous rib } \\
\text { bone }\end{array}$ \\
\hline Danisa/ 1995 & $\begin{array}{l}\text { Right } \\
\text { lateral } \\
\text { decubitus }\end{array}$ & $\begin{array}{l}\text { Subtotal } \\
\text { corpectomy }\end{array}$ & $\begin{array}{l}\text { - Kaneda device } \\
(n=15) \\
\text { - Z plate }(n=1)\end{array}$ & $\begin{array}{l}\text { - Tricortical iliac } \\
\text { crest bone graft } \\
\text { with morselized } \\
\text { rib graft }\end{array}$ \\
\hline Wood/ 2005 & $\begin{array}{l}\text { Right } \\
\text { lateral } \\
\text { decubitus }\end{array}$ & $\begin{array}{l}\text { Subtotal } \\
\text { corpectomy, } \\
\text { posterior wall of } \\
\text { vertebral body left } \\
\text { intact, no direct } \\
\text { decompression of } \\
\text { spinal canal }\end{array}$ & $\begin{array}{l}\text { - Transvertebral } \\
\text { body screws above } \\
\text { and below fracture } \\
\text { level } \\
\text { - Connecting dual } \\
\text { rods or Kaneda } \\
\text { plate }\end{array}$ & $\begin{array}{l}\text { - Fibular or } \\
\text { humeral strut } \\
\text { allograft } \\
\text { - Rib bone } \\
\text { autologous bone } \\
\text { graft }\end{array}$ \\
\hline $\begin{array}{l}\text { Stancic/ } \\
2001\end{array}$ & $\begin{array}{l}\text { Right } \\
\text { lateral } \\
\text { decubitus }\end{array}$ & $\begin{array}{l}\text { Subtotal } \\
\text { corpectomy with } \\
\text { spinal canal } \\
\text { decompression }\end{array}$ & $\begin{array}{l}\text { - Screw and plate } \\
(n=8) \\
\text { - Screw and rod } \\
(n=5)\end{array}$ & $\begin{array}{l}\text { - Tricortical iliac } \\
\text { crest bone graft }\end{array}$ \\
\hline Wang/ 2015 & $\begin{array}{l}\text { Right } \\
\text { lateral } \\
\text { decubitus }\end{array}$ & $\begin{array}{l}\text { Subtotal } \\
\text { corpectomy with } \\
\text { spinal canal } \\
\text { decompression }\end{array}$ & $\begin{array}{l}\text { - Cylindrical } \\
\text { titanium mesh cage } \\
\text { - Screw plate } \\
\text { fixation }\end{array}$ & $\begin{array}{l}\text { - Local autologous } \\
\text { bone graft }\end{array}$ \\
\hline Wu/ 2013 & $\begin{array}{l}\text { Right } \\
\text { lateral } \\
\text { decubitus }\end{array}$ & $\begin{array}{l}\text { Subtotal } \\
\text { corpectomy }\end{array}$ & $\begin{array}{l}\text { - Titanium mesh } \\
\text { cage } \\
\text { - Z plate with } \\
\text { screws }\end{array}$ & $\begin{array}{l}\text { - Local autologous } \\
\text { or allogeneic bone } \\
\text { graft }\end{array}$ \\
\hline
\end{tabular}

N.R.: not recorded 
Table 3. Positioning, method of decompression, fixation and fusion for posterior approach

\begin{tabular}{|c|c|c|c|c|}
\hline & \multicolumn{4}{|c|}{ Posterior } \\
\hline Author/Year & Position & Decompression & Fixation & $\begin{array}{l}\text { Supplemental } \\
\text { fusion }\end{array}$ \\
\hline $\begin{array}{l}\text { Hitchon } \\
\text { /2006 }\end{array}$ & Prone & $\begin{array}{l}\text { - Laminectomy and } \\
\text { disimpaction }(\mathrm{n}=10) \\
\text { - Transpedicular or } \\
\text { transfacetal } \\
\text { decompression } \\
(\mathrm{n}=8) \\
\text { - Ligamentotaxis } \\
(\mathrm{n}=7)\end{array}$ & $\begin{array}{l}\text { - Pedicle screws } \\
(n=18) \\
\text { - Pedicle screw + } \\
\text { hook }(n=6) \\
\text { - Hooks only } \\
(n=1)\end{array}$ & $\begin{array}{l}\text { - Demineralized } \\
\text { bone matrix (all } \\
\text { patients) } \\
\text { - Local autologous } \\
\text { bone graft or iliac } \\
\text { crest bone graft }\end{array}$ \\
\hline Danisa/ 1995 & Prone & $\begin{array}{l}\text { - Transpedicular } \\
\text { decompression } \\
(n=12) \\
\text { - Ligamentotaxis } \\
(n=15)\end{array}$ & $\begin{array}{l}\text { - Steffee plates } \\
\text { and pedicle } \\
\text { screws }(n=16) \\
\text { - Cotrel- } \\
\text { Doubousset rods } \\
\text { with hook and } \\
\text { claw system ( } n=4) \\
\text { - Harrington } \\
\text { distraction rods } \\
\text { and hooks ( } n=4) \\
\text { - Luque rings with } \\
\text { sublaminar wiring } \\
(n=3)\end{array}$ & $\begin{array}{l}\text { - Either iliac crest } \\
\text { bone graft or } \\
\text { allogeneic bone } \\
\text { graft in all patients }\end{array}$ \\
\hline Wood/ 2005 & Prone & $\begin{array}{l}\text { - No direct } \\
\text { decompression }\end{array}$ & $\begin{array}{l}\text { - Pedicle screw + } \\
\text { hook construct } \\
\text { over three to four } \\
\text { levels }\end{array}$ & $\begin{array}{l}\text { - Posterolateral } \\
\text { iliac crest bone } \\
\text { graft }\end{array}$ \\
\hline $\begin{array}{l}\text { Stancic/ } \\
2001\end{array}$ & Prone & $\begin{array}{l}\text { - Annulotaxis in all } \\
\text { - Partial or complete } \\
\text { laminectomy when } \\
\text { spinal canal } \\
\text { compromise }>50 \%\end{array}$ & $\begin{array}{l}\text { - Pedicle screw + } \\
\text { hook and rod } \\
\text { construct }\end{array}$ & $\begin{array}{l}\text { - Posterolateral } \\
\text { autologous bone } \\
\text { strips }\end{array}$ \\
\hline Wang/ 2015 & Prone & $\begin{array}{l}\text { - “posterior } \\
\text { decompression” }\end{array}$ & $\begin{array}{l}\text { - Pedicle screws } \\
\text { and rods one level } \\
\text { above and one } \\
\text { level below } \\
\text { fracture }\end{array}$ & $\begin{array}{l}\text { - Posterolateral } \\
\text { autogenous bone } \\
\text { graft }\end{array}$ \\
\hline Wu/ 2013 & Prone & $\begin{array}{l}\text { - Annulotaxis in all } \\
\text { - No direct } \\
\text { decompression }\end{array}$ & $\begin{array}{l}\text { - Pedicle screw } \\
\text { and rod fixation } \\
\text { one level above } \\
\text { and one level } \\
\text { below fracture }\end{array}$ & - N.R \\
\hline
\end{tabular}

\section{N.R.: not recorded}


Table 4. Risk of bias assessment of included observational studies according to the Newcastle-Ottawa Quality Assessment Scale

\begin{tabular}{|c|c|c|c|c|c|c|c|c|}
\hline \multirow{2}{*}{$\begin{array}{c}\text { First author, } \\
\text { Year }\end{array}$} & \multicolumn{4}{|c|}{ SELECTION } & \multirow{2}{*}{$\begin{array}{c}\text { COMPARABILITY } \\
\begin{array}{c}\text { Comparability of } \\
\text { cohorts }\end{array}\end{array}$} & \multicolumn{3}{|c|}{ OUTCOME } \\
\hline & $\begin{array}{c}\text { Representativeness } \\
\text { of cohort }\end{array}$ & $\begin{array}{c}\text { Selection } \\
\text { of non- } \\
\text { exposed } \\
\text { cohort }\end{array}$ & $\begin{array}{l}\text { Ascertainment } \\
\text { of exposure }\end{array}$ & $\begin{array}{c}\text { Outcome } \\
\text { of } \\
\text { interest }\end{array}$ & & $\begin{array}{l}\text { Assessment } \\
\text { of outcome }\end{array}$ & $\begin{array}{l}\text { Adequate } \\
\text { duration of } \\
\text { follow-up }\end{array}$ & $\begin{array}{c}\text { Adequate } \\
\text { follow-up of } \\
\text { cohort }\end{array}$ \\
\hline Danisa, 1995 & $*$ & $*$ & $*$ & $*$ & - & $*$ & $*$ & $*$ \\
\hline Stancic, 2001 & $*$ & $*$ & $*$ & $*$ & - & $*$ & $*$ & $*$ \\
\hline Hitchon, 2006 & - & - & $*$ & $*$ & - & $*$ & $*$ & $*$ \\
\hline Wu, 2013 & - & - & $*$ & $*$ & - & $*$ & $*$ & $*$ \\
\hline
\end{tabular}


Table 5. Risk of bias assessment of included RCTs based on Cochrane Handbook for Systematic Reviews of Interventions

\begin{tabular}{|c|c|c|}
\hline Criteria & Wood, 2005 & Wang, 2015 \\
\hline $\begin{array}{l}\text { 1. Was the method of randomization } \\
\text { adequate? }\end{array}$ & Unclear & Yes \\
\hline 2. Was the treatment allocation concealed? & No & No \\
\hline $\begin{array}{l}\text { 3. Was the patient blinded to the } \\
\text { intervention? }\end{array}$ & No & No \\
\hline $\begin{array}{l}\text { 4. Was the care provider blinded to the } \\
\text { intervention? }\end{array}$ & No & No \\
\hline $\begin{array}{l}\text { 5. Was the outcome assessor blinded to the } \\
\text { intervention? }\end{array}$ & No & Yes \\
\hline $\begin{array}{l}\text { 6. Was the drop-out rate described and } \\
\text { acceptable? }\end{array}$ & Yes & Unclear \\
\hline $\begin{array}{l}\text { 7. Were all randomized participants } \\
\text { analysed in the group to which they were } \\
\text { allocated? }\end{array}$ & Yes & Yes \\
\hline $\begin{array}{l}\text { 8. Are reports of the study free of } \\
\text { suggestion of selective outcome } \\
\text { reporting? }\end{array}$ & Yes & Unclear \\
\hline $\begin{array}{l}\text { 9. Were the groups similar at baseline } \\
\text { regarding the most important prognostic } \\
\text { indicators? }\end{array}$ & Unclear & Yes \\
\hline $\begin{array}{l}\text { 10. Were co-interventions avoided or } \\
\text { similar? }\end{array}$ & Yes & Unclear \\
\hline $\begin{array}{l}\text { 11. Was the compliance acceptable in all } \\
\text { groups? }\end{array}$ & Unclear & Unclear \\
\hline $\begin{array}{l}\text { 12. Was the timing of the outcome } \\
\text { assessment similar in all groups? }\end{array}$ & Yes & Unclear \\
\hline
\end{tabular}

